\title{
La UNAM y la Facultad de Economía en la historia de México
}

Algún tratadista destacado e influyente en el ámbito académico definió a la universidad de manera precisa, como la ciudad del conocimiento, a lo que nosotros agregaríamos que ciertamente es un espacio libre en donde se piensa, se crea, se investiga y se divulga en un ámbito de la más completa libertad, ¿acaso no lo hace la Universidad Nacional? paradigma por excelencia de la universidad mexicana que se ganó a pulso su autonomía, base medular de la libertad de cátedra. Con esos insumos ha podido crear un modelo ad hoc de institución educativa mexicanizada, como lo planteó Justo Sierra en su memorable discurso en ocasión de la inauguración de nuestra Máxima Casa de Estudios, aquel 27 de septiembre de 1910, en el recinto del "Anfiteatro Bolívar", que bien podría considerarse como el símbolo de la libertad de expresión, para reconocer, además, cómo años más tarde lo hizo Vasconcelos, de retomar ese principio para fundirlo en el escudo universitario -el águila y el cóndor- y en su lema, que expresa a los cuatro vientos, la majestad y la presencia de la gran patria latinoamericana, y que en tiempos recientes, desde los ámbitos de Ciudad Universitaria, las nuevas generaciones valoran su grandeza.

Ciertamente, la Universidad $\mathrm{Na}-$ cional Autónoma de México (UnAm) en un ingente universo en donde cotidianamente se piensa, se crea, se discute, se investiga, y así, constantemente, se van formando generaciones de profesionistas que servirán a México; porque hay que tener presente que el modelo educativo actual está integrado -además del conocimiento científico y tecnológico respectivos-, por un aval de carácter humanístico y social.

Los egresados de la UNAM - una de las más grandes del mundo y la más importante de América Latinaaprenden y practican el criterio profesional, lo que les permite ser creativos e innovadores, de tal modo que podrán cambiar la realidad en todos sus sentidos, esto es, socioeconómico, político y cultural.

Pero la UNAM tiene su base fundamental en la Escuela Nacional Preparatoria, fundada en 1867 y que constituye la institución que en su momento -como expresión del juarismo laico, que crearía Gabino Barreda-, adopta el credo positivista de Comté, y que como señala Charles Hale, en su libro La Transformación del Liberalismo en México a finales del siglo XIX, dejó de ser una mera ideología y se convierte en soporte de lucha contra unas instituciones y un orden social establecidos, para convertirse en un mito político unificador, es decir, elemento aglutinante de nuestra nacionalidad. 
Agrega Hale, "el liberalismo posterior a 1867 también encontró un ambiente unificador nuevo, influido, en parte, por la introducción de la filosofía positivista, que impacta no sólo a la política, sino a la educación superior. En este caso la Escuela $\mathrm{Na}$ cional Preparatoria y tendría como sede al antiguo edificio del Colegio de San Ildefonso, donde enseñó José María Luis Mora, que representaba en ese entonces, un proyecto modernizador.

Entre los teóricos destacados que representaron el influjo de esa corriente, se encontraban, el propio Justo Sierra, así como varios ideólogos que destacarían en ese entonces como Porfirio Parra, Francisco G. de Cosmes, Francisco Bulnes, Emilio Rabasa, Andrés Molina Enríquez, Horacio Barreda y Agustín Aragón. Pero también hay que mencionar a los teóricos fundamentales del liberalismo mexicano, continuadores de las ideas de Mora, entre los que destacan: Mariano Otero, Ignacio L. Vallarta; Melchor Ocampo, entre otros. Así mismo, Joaquín Eguía Liz, que fuera el primer rector de la UNAM, creada en 1910, y Ezequiel A. Chávez; partícipe de la elaboración de ese proyecto, como integrantes y egresados de lo que ha sido y es la Escuela Nacional Preparatoria.

Pero no podemos pasar por alto el significado y razón de ser de lo qué es y ha sido la Universidad, en su sentido genérico, como la considera, por ejemplo Ortega y Gasset, puntos de vista ideológicos que no obstante expresados hace tiempo conservan matices de frescura y de actualidad.

Pero debemos tener muy presente el significado de esa simbiósis, profunda e irreversible que significa la transculturación del espíritu y la raza, en su proyección social y humanística que ya había avizorado el propio Sierra y que Vasconcelos lo interpretaría con profundo sentimiento filosófico, y que retomaría el movimiento estudiantil de 1929, que tiene como trasfondo el mensaje de la declaración de los estudiantes de Córdoba, Argentina, de 1918; ciertamente un año proteico porque durante su transcurso se registran acontecimientos trascendentes para un siglo violento, que se iba transformando a gran prisa. En efecto, es el año de la gran crisis económica que estuvo a punto de acabar definitivamente con el sistema económico determinante, y que el replanteamiento de la teoría económica por J. M. Keynes-que causó toda una revolución, y la puesta en marcha de la política del New Deal, por el presidente Roosevelt, de Estados Unidos-, puso a salvo un sistema económico que por su naturaleza afectó a ese tipo de fenómenos que han sido recurrentes.

Pero eso no fue todo, pues el año 1929, en México posrevolucionario, registra la lucha por la autonomía de 
la Universidad Nacional, iniciada al principio, por los estudiantes de la Facultad de Jurisprudencia y como corolario, en febrero de ese mismo año inicia sus actividades un modesto organismo creado por Narciso Bassols, integrante de la famosa generación de 1915, director por esas fechas de la citada Facultad de Jurisprudencia, la llamada sección de Economía, en donde se estudiará una nueva profesión universitaria, la licenciatura en Economía, profesión desconocida en el México de esa época, y que se hacía necesaria, toda vez que los gobiernos revolucionarios estaban laborando contra-reloj, para convertir en realidad los postulados de dicha Revolución.

En efecto, los gobiernos de Obregón y de Calles habían realizado acciones importantes para la modernización de la estructura económica de México, donde destaca la reorganización del sistema monetario, desquiciado por los efectos del movimiento armado, así, con la participación de Manuel Gómez Morín en la creación del Banco de México como banco central de la nación, Calles llevó a cabo importantes actos de gobierno, como la creación de la Comisión Nacional de Caminos, la Comisión Nacional Bancaria, la Comisión Nacional de Irrigación, entre otros, que en su conjunto, se consideran como Reformas de Calles, que se complementan con la reforma hacendaria, cuyo artífice fue Alberto J. Pani, ingeniero de profesión; el segundo objetivo fue la reorganización de la política fiscal; el tercero, la creación de un sistema bancario que respondiera a las expectativas de las políticas económicas del régimen.

Para integrar éste proyecto, fue la modernización y profesionalización de las fuerzas armadas llevada a cabo por el Gral. Joaquín Amaro y como corolario, la unificación de la familia revolucionaria en un partido político único. Ante el reto formidable de realizar este proyecto renovador en un lapso rápido e irreversible, surgieron retos muy importantes. Esta cuestión se dejó sentir ante la falta de profesionales en la ciencia económica.

El país requería de manera inmediata la preparación de ese tipo de especialista, que ya por ese entonces, a nivel mundial, estaba desempeñando un papel destacado en los países europeos: Inglaterra, Francia, Alemania y por supuesto Estados Unidos. Al respecto, hay que recordar que en varias universidades de esos países se estudiaba la ciencia económica y que además ya existía una corriente sui generis de lo que bien podría considerarse como pensamiento económico norteamericano, Joseph Dorfman, El pensamiento económico en la Civilización Norteamericana y que, además, por esos tiempos se funda la American Economic Assotiation. 
Un hecho relevante para la época, habría de ser la creación de la London School of Economics and Political Science, que deslumbró a Daniel Cosio Villegas, en aquellos tiempos de su dorada juventud; deslumbrado, dice en sus Memorias, por esa creación de Sidney y Beatrice Webb, que había conocido a través de sus libros, en especial por su Fabian Essays, por su tesis de la creación de un socialismo gradual, origen, de lo que sería más tarde, el Labour Party Inglés.

Durante el tiempo que permanece Cosío Villegas en Londres, asistía con frecuencia a las conferencias y seminarios de Harold J. Laski en el apogeo del su talento y de su fama.

El país requería, apenas de manera inmediata de la creación de esa nueva profesión, qué mejor ocasión que crearla en aquel proteico 1929 dentro de la Universidad Nacional, que en 1929 estaba bajo la rectoría de Antonio Castro Leal - uno de los siete sabios mexicanos- y acerca de determinar de quién fue la idea, conlleva una versión controvertida Cosío Villegas se adjudica la paternidad, mientras la versión más admitida recae en Narciso Bassols, por esas fechas director de la Facultad de Jurisprudencia y Ciencias Sociales.

Acerca de los orígenes y expansión de la carrera de economía, se han elaborado varios libros. Sin embargo, una de las más recientes $\left(13^{\mathrm{a}}\right.$ edición en español 2003, publicada por el
Fondo de Cultura Económica) de la autoría de la socióloga norteamericana Sarah Baab "Proyecto: México" -los economistas del nacionalismo al neoliberalismo- cuyo sentido a grosso modo, expresa la necesidad de esa primera época, de la realización de los postulados de la Revolución Mexicana, y la modernización del país, en su enfoque macroeconómico, con influencia del nacionalismo revolucionario de esa primera etapa, pero con un contexto humanista, inclinado marcadamente al pensamiento de izquierda. Así, desde sus inicios figura esa tendencia en todos y cada uno de sus planes de estudio.

Pero, en aquellos años turbulentos tanto en el país, como en el mundo, la creación de una nueva profesión, en México, con esa tendencia, era una herejía. Por esas fechas, escenario ya de luchas estudiantiles, alguien tuvo la ocurrencia de pergeñar unos versos ripiosos aludiendo a la Economía Política, “...Pues esta ciencia imprudente, molesta al capitalista y si el pueblo la interpreta, se convierte en dinamita..." huelga los comentarios, diríamos.

Sin embargo, ha habido una evolución de la profesión de economista en México, y la tendencia destacada actualmente es la de consolidarse como un bastión de los modelos neoclásicos de acuerdo con la corriente estadounidense, que señorea el ámbito y de los tecnócratas que promueven 
el libre mercado aquellos "yuppies" pioneros, antecedente de la oleada de los Chicago Boys, de la corriente del inefable Milton Friedman (Después de la desaparición del modelo clásico del socialismo real en lo que fuera la URSS y el fin de la "Guerra Fría", el sistema económico predominante, se consolida definitivamente, y esto da lugar a afirmar que lo históricamente correcto era el proceso irreversible de integración y de consolidación de la sociedad económica internacional, tesis que a su vez genera el irreversible fin de la historia, y como si fuera poco, la prevalencia del pensamiento socio político y económico único).

Sin embargo, a pesar de la crítica de Daniel Cosío Villegas en sus $M e$ morias y del análisis serio y sistematizado de Sarah Baab en su libro de referencia, consideramos que la actual Facultad de Economía, ha cumplido con sus propósitos de acuerdo con el momento histórico en que fue creada como simple Sección de Economía dentro del organigrama de la entonces Facultad de Jurisprudencia; porque era la institución que requería el país. La idea original se adjudica a Bassols, aunque Cossio Villegas asegura que fue él quien tuvo tal iniciativa. Y como si fuera poco, abjura de quién tuvo la peregrina idea de que el aula más importante de nuestra Facultad, ostente el nombre de quien para Don Daniel, sólo fue un jurisperito.
Hay que señalar que la institución pasa a su segunda etapa, es decir, como Escuela Nacional de Economía cuando sus estudiantes y alumnos encuentran un amplio campo de experimentación profesional en el Banco de México así como en la Secretaría de Hacienda, Nacional Financiera y Seguro Social y en otros organismos fundados a lo largo de lo que va conformando la institucionalidad del Estado mexicano, como habría de ser, así mismo, la banca de desarrollo, semillero de esos egresados.

Así, en términos generales, podemos afirmar que los egresados de la actual Facultad de Economía de la Universidad Nacional en cierta ocasión, durante un acto académico en el mal denominado Auditorio "Narciso Bassols", según Cossío Villegas, el rector Sarukan, afirmó que se sentía orgulloso en el claustro académico por donde habían impartido cátedra, grandes maestros; han prestado sus servicios en todas y cada una de las instancias del sector público federal, así como en cargos de elección popular, inclusive en la primera magistratura del país, lo mismo que en lo que se refiere al ámbito municipal.

Con la puesta en marcha del proyecto neoliberal, que incumbe a los intereses del sector privado, como se sabe, y como lo analiza la socióloga Sarah Babb en su libro de referencia, serían organismos privados de educación superior, como es el caso del 
Instituto Tecnológico Autónomo de México (ITAM), y más tarde el Instituto Tecnológico y de Estudios Superiores de Monterrey, en donde se enseñaría economía neoclásica, obviamente $\sin$ la retórica socialista. Desde el nacionalismo hasta el neoliberalismo los economistas mexicanos han estado en el centro de la toma de decisiones que impactan a todos. Sus "supuestos", para bien o para mal, se han traducido en efecto, en políticas públicas que determinan la vida de todo un pueblo.

- Pero repensando la trayectoria vital de la Facultad de Economía, hay que mencionar que, en el proceso de su integración ha pasado por tres etapas:

- La primera, en sus orígenes, como Sección de Economía adscrita a la Facultad de Jurisprudencia, durante el breve lapso en que fue director Narciso Bassols.

- La segunda, corresponde a su conversión en Escuela Nacional de Economía, en 1935, debido al esfuerzo de Enrique González Aparicio, que fue su primer director. Sería, en el edificio que ocupó en República de Cuba 92, en los confines del barrio universitario de San Ildefonso, donde bajo la dirección del maestro Gilberto Loyo, la profesión se consolidó definitivamente.

- La tercera etapa de su devenir académico habría de ser ya ubicada en su recinto en Ciudad Universitaria, donde gracias a la labor y el esfuerzo de su director, José Luis Ceceña Gámez, que logra establecer la
División de Graduados, con lo que se convierte en Facultad, en el año de 1974. Bajo su comprensiva dirección, los estudiantes ganaron representación paritaria permanente junto a los profesores en el Consejo Técnico.

Queremos, así mismo, agregar algo más al respecto. La enseñanza de la economía, en lo que hoy día es la Facultad de Economía, ha pasado por cuatro grandes corrientes del pensamiento económico que son, más o menos, las siguientes:

- La primera, durante sus orígenes, influencia determinante de la Escuela de Economía de Londres. Ya que varios de sus primeros profesores estudiaron ahí: Daniel Cosio Villegas, Víctor L. Urquidi, Miguel Palacios Macedo, y el mismo Enrique González Aparicio.

- La segunda corresponde a la participación de varios profesores europeos, exiliados políticos en los años de la posguerra de la Primera Guerra Mundial (1914-1918), y por las persecuciones políticas de los gobiernos totalitarios en Alemania e Italia. Entre ellos destacan el alemán Alfons Godsmith; el suizo Fritz Bach y el italiano Francisco Frola. Vendría también el húngaro Lazslo Radvanyi, que a su regreso a lo que fuera la Alemania Democrática adoptaría el nombre de Johan Schmidt. Radvanyi, ciertamente era un genio. Conocía a la perfección las distintas corrientes del pensamiento económico; su clase era un pozo de sabiduría, considerada en verdad 


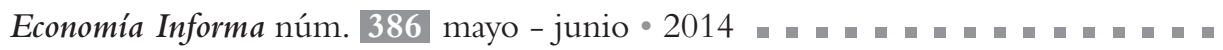

como una Cátedra Magistral. Fue alumno de Max Weber. Cuando terminó su curso, a nuestro grupo nos llevó a cenar a un elegante restaurante que estaba en la Ave. Álvaro Obregón, en la Roma. Filiberto Ney Morales, fue su adjunto.

- Al final de la Guerra Civil Española, -1936-1939- en tiempos del Gral. Cárdenas, vendrían a México como exiliados políticos algo así como 25 mil españoles republicanos. Entre ellos, llegarían numeroso profesores universitarios, que al incorporarse a la Universidad Nacional, renovarían la educación superior. Muchos de ellos, se incorporaron a la entonces Escuela Nacional de Economía, constituyendo una corriente nueva y vigorosa de la enseñanza de esa ciencia. Entre ellos, hay que citar a Antonio Sacristán Colás; Manuel Sánchez Sarto; José Mingarro San Martín; Luis Recaséns Siches; Gabriel Franco; Vicente Herrero; Alfredo Lagunilla Iñarritu; Javier Márquez; Julio Luelmo; Carlos Sáenz de la Calzada; José Medina Echeverría; Cristóbal Lara Bautell entre otros. Wenceslao Roces, por su parte tradujo El Capital. El caso de Ramón Ramírez Gómez es especial. ¡Ah! y en España, se desempeñó como maestro normalista. Durante la Guerra Civil, fue miliciano en las fuerzas armadas de la República. Cuando viene a México, estudia la profesión de economista en la ENE, y después inicia su labor académica como profesor adjunto del maestro Francisco Zamora en la clase de Teoría Económica. Después, impartiría la clase de Teoría Monetaria de la que elaboraría un libro de texto explicado desde el punto de vista marxista. En el movimiento estudiantil de 1968 , participa como observador, de tal manera, que poco después elaboró un libro donde explica las causas sociales y políticas de esos sucesos, obra clásica en estos tiempos. Su biblioteca particular la donó a la institución, cuyo acervo forma parte del acervo de la biblioteca de la División de Graduados, misma que lleva su nombre. Fue un docente querido y respetado por toda la comunidad de ese, nuestro claustro académico.

- La cuarta corriente vendría a ser la constituida por los exiliados políticos de varios países sudamericanos que tuvo lugar en los años ochenta del siglo xx. Fue numerosa y por supuesto dieron a conocer nuevos e inéditos planteamientos de esa disciplina. Entre ellos figuran, Agustín Cueva, ecuatoriano; Adolfo Gilly, y Alejandro Labat, autor de Los otros capitalismos, obra publicada por el FEC, argentinos; Susana Becerra, argentina, de la Universidad de Córdoba, por cierto fallecida recientemente en su tierra natal. También figuran Rosa Cuminsky, argentina; Pedro Paz; Sergio Bagú, argentinos; el chileno Julio López; la argentina Mónica Blanco; los brasileños Theotonio Dos Santos, Vania Bambirra; Fernando Noriega Ureña, boliviano, ocupó la División del Sistema Abierto de la Facultad de Economía, es autor de Teoría del desempleo, la distribución y la pobreza, su obra es una innovación a la Teoría del Empleo; Gerardo Aceituno, Alberto Spagnolo, argentinos, así como Hugo Pipitoni; el brasileño Raimundo Arroio; el brasileño Ruy Mauro Marini; el boliviano René Zavaleta; el uruguayo Miguel Abdala; el argentino Fernando Fotnaylber. Los chilenos, Pedro Vuskovic 
y Jaime Zurita; el peruano Miguel Ángel Alza Araujo; el argentino Rodolfo Puiggrós, que fuera rector de la Universidad de Buenos Aires (“...el ejemplo de los revolucionarios auténtico, de los que se entregan a su causa con pasión integral, de los que no miden los riesgos, ni esperan que otros se jueguen por ellos en nombre de una falsa superioridad intelectual." (La Jornada, 16-03-2011) Eran los tiempos en que como recordó Teresita Aguirre, en que la Facultad de Economía se convirtió en un centro de generación y difusión del pensamiento económico latinoamericano de vanguardia.

Hemos hecho, pues, un largo, sinuoso y complejo recorrido por la trayectoria histórica que comprende la vida, la existencia, el devenir académico de nuestra Facultad, desde aquellas fechas heróicas, precarias, austeras, de incertidumbre en que inició sus tareas docentes aquel lunes 20 de febrero de 1929, cuando en el recinto acogedor situado al lado derecho del cubo del zaguán, de la Facultad de Derecho y Ciencias Sociales, sito en San Ildefonso 28, en el corazón del famoso Barrio Universitario, ahora considerado simplemente como Centro Histórico de la Ciudad de México, ante un grupo atiborrado y heterogéneo de estudiantes de diferentes edades y condiciones sociales, el maestro Daniel Cosío Villegas dio comienzo a su curso de Teoría Económica, que seguramente por la forma en que
Cosío Villegas manejaba el discurso académico, conmovió, cimbró, cautivó a aquellos primeros alumnos, la generación primera, de una profesión nueva y desconocida en México, en un México que en esos momentos de plena coyuntura económica, social y política, como dirían los economistas modernos, luchaba por reencontrarse en el contexto de una nueva realidad, después de un proceso muy intenso de cambios, de evoluciones, de propósitos de superación en todos los sentidos de la palabra.

Sin duda, ya dentro de su configuración como Escuela Nacional de Economía, y después como Facultad de Economía, este organismo universitario ha participado intensamente en las luchas sociales de México, haciendo oír su voz, su presencia, ha sido, por tanto, la de uno de los planteles universitarios de mayor empuje revolucionario, donde el pensamiento y la acción marchan de manera concomitante, donde sigue siendo la bandera la enseñanza crítica.

¡Ah! Las luchas emprendidas por tantas y tantas generaciones de jóvenes estudiantes en pro de las reivindicaciones sociales de México y de su pueblo, de sus clases sociales marginadas y oprimidas. Siempre presentes, el pensamiento y la acción, todo envuelto en suave halo de la esperanza y de los arrestos juveniles. Generación del 68, y también del 29, que marcan hitos indelebles en la vida universitaria 
del México contemporáneo. Ocho y pico décadas después, el siglo irreversible de la modernidad, en condiciones distintas a las citadas, la UNAM se debate por alcanzar un nuevo estrato de modernidad, y seguir presente en los destinos de México.

Cuantos y cuantos jóvenes, en pos de una ideal, han luchado desde las aulas universitarias, desde las de la Escuelas Nacional de Economía, y han delineado estrategias sustanciales. El debate por los planes de estudios, por la Economía Política como eje conductor, por la democratización de la enseñanza, por los organismos paritarios de gobierno, y todo porque la Universidad es pueblo, es la otra cara del pueblo de México, desde donde como quería la voz vasconceliana, el espíritu hablará por la raza, y en estos tiempos difíciles de la modernidad, esa misma grey universitaria, representada por las generaciones de estudiantes finiseculares y también los novoseculares, clama a grito herido, ente los impactos del nuevo proyecto neoliberal,: "si no hay raza, quién hablará por el espíritu..."

Trayectoria heróica de la antigua Escuela Nacional de Economía, convertida en Facultad desde los años setenta, cuya repercusión sigue siendo importante en los ámbitos universitarios de México y de Latinoamérica. Por sus aulas, decíamos, han desfilado muchos maestros distinguidos y famosos que han dejado huella indeleble en la historia académica de esa institución.

Ha sido, pues, un gran foro abierto a todas las corrientes del pensamiento económico, y también escenario de debate y de luchas sociales y políticas del México de los últimos cuarenta años.

Estudiar y repensar los vericuetos de la ciencia económica desde el aula, desde la cátedra, promover la investigación y el debate de altura, son tareas cotidianas que desde siempre se han practicado en esa institución.

¡Ah! El léxico que manejan los economistas tan abstracto, tan difícil de entender, y con que prosopeya lo utilizan. Hay elegancia cuando explican la problemática económica y qué medidas hay que llevar a cabo para superarla. Con sus ex post, ex ante, Ceteris Paribus, se apoyan en sus propuestas desesperadas e inquietantes, como diría George J. Stigler, cuando consideran que en primera instancia, el economista es un predicador, un valor académico relativamente menor es el énfasis sobre las insignias de la academicidad. La forma de trabajar adquiere un valor independiente de su contenido; un investigador debe ser ilustrado y su trabajo realizado con instrumentos distinguidos. La antigua enseñanza es a menudo un elemento constituyente de sus atavíos, pero también lo es el dominio de los poderosos métodos matemáticos. 
Noble tarea, heróica tarea la de la enseñanza a nivel universitario y más cuando se trata de una disciplina como lo es la ciencia económica, tan llena de vicisitudes, de variables, de vericuetos, de verdaderos laberintos donde el maestro, el investigador; el alumno guiado por sus mentores, tendrá que encontrar el camino correcto, y extraer las enseñanzas adecuadas, aquellas que han de servir para progresar, para diseñar estrategias y políticas económicas que sirvan a México, porque, ciertamente, la ciencia económica tiene dos aspectos, dos caras, una positiva, es decir, aquella que sirve para elaborar políticas económicas que redunden en el bienestar de las familias, y la otra que vienen a ser la parte negativa, la que procura la creación de lo que Viviene Forrester llama, paladinamente, "El horror económico", y lo explica, lo desmenuza, y demuestra sus hipótesis, y sus postulados, porque advierte que un mundo desaparecido pretende contra viento y marea, perpetuarse mediante políticas artificiales a modo de configurar "una extraña dictadura"

Un mundo, en fin, en el que nuestros conceptos del trabajo y por ende del desempleo carecen de contenido y en el cual millones de vidas son destruidas y sus destinos aniquilados. La docencia, la investigación, la enseñanza misma, tiene por tanto, desde este punto de vista, una gran responsabilidad, que es la de orientar de manera objetiva las mentes juveniles, que son por esencia entidades manejables, moldeable, fáciles de influir, fáciles de tergiversar.

Dos generaciones significativas en las luchas estudiantiles, lucha que tuvo repercusión nacional, la del 29, la generación de la autonomía y la del 68, la de la apertura democrática en un México que ya requería cambios profundos en sus estructuras.

En estos casos, la profesión de economía, en el contexto de esos dos grandes proscenios, en medio de esos dos parteaguas de la vida nacional, se había de nutrir, se había de retroalimentar, en el segundo caso, y su participación, en muchos aspectos, habría de ser determinante.

La ejecutoría del 29, nos dice Baltasar Dromundo, corrigió, elevándola a juicio definitivo transformándola por los hechos, la opinión moral que realmente merecían los jóvenes de esa época atormentada que agitó a las conciencias y a toda la juventud como si fuera un árbol áureo de la nación, con lo que vino a tierra lo que de podrido permanecía adherido a sus ramas frondosas: caía del árbol lo que era material de desecho y rápidamente reconstruido por los vertederos políticos de la hora, las horas del México del 29.

“...La universidad se hizo autónoma por la revolución de nuestra palabra, nuestra huelga y nuestra sangre, han pasado ya cincuenta años y 
otras generaciones desplazaron a los hombres de aquella época. Unos siguieron leales a sus ideas de entonces, otros han tomado diferentes caminos, más la mayoría con honestidad de conducta y probada honradez intelectual." diría, años más tarde Carlos Zapata Vela.

"Hay una primera razón -dijo Bassols en el acto inaugural- para estimar que el año de trabajos que comienza, significa la iniciación de un ciclo nuevo. Hoy se abre a los estudiantes de la Universidad una nueva carrera. Ahí están, sentados entre vosotros, conviviendo con los estudiantes de derecho, jóvenes que confiados en nuestros ofrecimientos y nuestras palabras, han abandonado el camino de la clásica profesión de abogado, para empezar un estudio organizado, coherente de nuestra economía nacional... Esta realidad viva -continuó Bassolses un éxito; pero es también un compromiso. La presencia de estos jóvenes entre nosotros nos hará recordar todos los días que hay ya unos cuantos espíritus valientes que supieron atravesar un mundo de prejuicios para emprender, confiados en nosotros, una carrera cuyo porvenir, cuyo sentido necesitamos puntualizarles hoy."

Pero a pesar de todo, la nueva profesión fue cobrando prestancia, reconocimiento y respeto, no solo en el ámbito universitario, sino también en el mundial, especialmente en el latinoamericano.
Institución briosa y revolucionaria, pero ante todo universitaria, fue objeto durante una visita a sus instalaciones en Ciudad Universitaria, del Rector Barros Sierra, que le hizo exclamar más o menos las siguientes palabras: “... ¡Vamos, con esta autónoma Escuela Nacional de Economía...!"

Pero, nuestra gran casa de estudios, la Universidad Nacional, la de Justo Sierra, Antonio Caso, José Vasconcelos y de muchos más, es y será en una primera instancia "Maestra de la vida". El alma máter por excelencia de muchas generaciones de mexicanos capacitados en sus aulas con el único propósito de servir a México.

Para concluir con estos comentarios, se tiene el propósito de conmemorar el octogésimo quinto aniversario, tanto de la autonomía de la Universidad Nacional como de la creación de lo que hoy es la Facultad de Economía, vamos a mencionar a varios economistas extranjeros que en diversas instancias hicieron acto de presencia en el claustro académico, para dictar trascendentes cátedras magistrales.

Durante su estancia en el edificio de Cuba 92, allá en el barrio universitario de San Idelfonso, entre otros: Joseph Schumpeter, Corrado Gini, Eric Zimmerman, en sus instalaciones en Ciudad Universitaria; Fritz Katz, Joan Robinson, Alfred Sauvy, Emil James, 
Oskar Lange, Celso Furtado, Felipe Herrera, Oswaldo Sunkel, Raúl Prebish, Ernest Mandel, John Gailbraith, James J. Heckman (Premio Nobel de Economía, 2000) y Paul Sweezy.

Resultaría prolijo mencionar a los muchos egresados que han destacado en el ejercicio de la profesión de economista: secretarios de estado, embajadores, diputados, senadores, gobernadores, presidentes municipales; así como destacados empresarios e intelectuales de vanguardia. Asimismo, de sus aulas han egresado importantes funcionarios de organismos intenacionales.

Por solo citar alguno, ahora recuerdo a Roberto Martínez Le Clainche quien fue uno de los primeros doctorantes en Economía que hubo en México, obtuvo el grado en la Universidad de París -La Sorbona: tres-. Los otros dos fueron, Josué Sáenz, que estudió en Cambridge con Keynes y Alfredo Navarrete Romero, en Harvard. Martínez Le Clainche fue profesor de la ahora Facultad de Economía. Ocupó el cargo de Secretario General de la misma, durante la gestión del maestro Torres Gaitán. Le tocó llevar a cabo la mudanza del edificio de Cuba 92, a la Ciudad Universitaria. Entre su obra escrita, figura su libro sobre Teoría monetaria, asignatura que impartió en la que fuera Escuela Nacional de Economía.
Fue consultor de la CEPAL, analista del Banco de México, director general de Estudios Económicos de la Secretaría de Industria y Comercio; jefe de Asesores de Estudios Económicos en el IMss; embajador de México en Bélgica, gran ducado de Luxemburgo y representante permanente de México ante las comunidades Europeas; embajador y representante de México ante los organismos de Naciones Unidas con sede en Ginebra; embajador de México en el Uruguay y representante permanente de México primero ante la ALADE y posteriormente ante la ALADI.

En sus memorias comenta cómo se efectuaban las clases en la Universidad de París -La Soborna- donde estudió el doctorado "Fuente de la Sabiduría Universal" en donde los alumnos rompan la solemnidad del claustro para comentar en voz alta o hacer mofa de lo que el maestro explicaba...

Para concluir esta reseña, en donde se relata solo destellos aislados de lo que ha sido la trayectoria, no solo de la ahora Facultad de Economía, sino de sus maestros, alumnos y egresados, queremos hacerlo mencionando algo más acerca de Roberto Martínez LeClainche, que haciendo un esfuerzo poco común, logró satisfacer su gran deseo, estudiar y doctorarse en la Universidad de París. 
Martínez LeClainche, inició sus estudios en la ENE, pero su deseo era, como decimos, continuarlos en $\mathrm{Pa}-$ rís. De esa experiencia juvenil, nos da cuenta en su libro Destellos de París que publicó la Universidad Nacional, del que Víctor L. Orquidi comenta que se trata de una obra en que resalta la agudeza de sus observaciones, del sentido de ironía y de humor que demuestra y a la vez de la franqueza con que trata temas difíciles de su vida personal en esa ciudad.

También menciona a quienes fueron algunos de sus maestros, por cierto muy conocidos en nuestro medio. Cita a Bertrand Nogaró en Economía Política; que desarrolló como tema especial "La utilización de los datos cuantitativos en economía política"; Louis Baudin en Historia de las Doctrinas Económicas y de los hechos económicos, cuyo programa especial versó sobre "Algunas experiencias socialistas"; Emile James en el curso de Economía Social Comparada, dedicado esa vez a "Las instituciones internacionales de progreso social" y, finalmente, André Marchal en Estadística, que desarrollaría el tema "Métodos Estadísticos y Teoría Económica". También comenta cómo fue el examen para obtener el grado. Se admiró por la forma tan simple en que los sinodales se lo otorgaron. Recuerda, que el día de la ceremonia, revestida de boato semi-feudal, fue entrando uno por uno de sus sínodos. De manera informal, entablaban breve plática, una que otra pregunta, y de repente, exclamaban "¡es bastante; concluyó mi interrogatorio! Es todo..."

Como se ve, nuestra Facultad tiene y ha tenido una gran trayectoria, de acuerdo con la presencia de la Universidad Nacional. 